\title{
Paradoxical Stimulatory Response of Remanent Sphincter of Oddi to Buscapina After Endoscopic Sphincterotomy
}

\author{
Zoltán Berger* and Ana María Madrid S* \\ Division of Gastroenterology, Clinical Hospital Universidad de Chile, Santiago, Chile
}

\section{Background/Aims}

Endoscopic removal of bile duct stones has become the treatment of choice, which includes endoscopic sphincterotomy (EST) in the majority of cases, destroying at least partially the Oddi sphincter (OS). Loss of sphincter function in variable grade has been described, but changes in innervation are not known.

\section{Methods}

Endoscopic manometry of OS was performed in 14 patients after EST with specialized perfused catheter. Pressure values were registered before and after $10 \mathrm{mg}$ Buscapina injected intravenously.

\section{Results}

Choledocho-duodenal pressure gradient was absent in all of 14 patients. Basal OS pressure was zero in 7 and conserved in normal range in the remaining 7. Phasic motor activity was registered in 11 patients and was absent in 3 patients. After $10 \mathrm{mg}$ Buscapina intravenous injection, instead of habitual inhibition, increase in basal OS pressure and in frequency of phasic contractions was observed in 9 patients. This response was not related to age of patients, neither with time elapsed between the EST and manometry, nor the estimated size of papillotomy orifice. Duodenal peristalsis was invariably inhibited in all patients.

\section{Conclusions}

EST destroys not only the smooth muscle of OS, also alters the innervation interrupting the duodeno-sphincteric nerve circuit. This finding questions the use of Buscapina or other anticholinergic agent as spasmolytic in patients after EST.

(J Neurogastroenterol Motil 2021;27:632-638)

\section{Key Words}

Cholinergic antagonists; Manometry; Motor activity; Spincter of Oddi; Sphincterotomy

Received: August 13, 2020 Revised: October 21, 2020 Accepted: December 28, 2020

(a) This is an Open Access article distributed under the terms of the Creative Commons Attribution Non-Commercial License (http://creativecommons. org/licenses/by-nc/4.0) which permits unrestricted non-commercial use, distribution, and reproduction in any medium, provided the original work is properly cited.

${ }^{*}$ Correspondence: Zoltán Berger and Ana María Madrid S are equally responsible for this study.

Zoltán Berger, MD

Hospital Clínico Universidad de Chile, Dr. Carlos Lorca Tobar 999, Independencia, Santiago 8380456, Chile

Tel: +56-2-2978-8350, E-mail: berger.zoltan@gmail.com

Ana María Madrid S, MD

Hospital Clínico Universidad de Chile, Dr. Carlos Lorca Tobar 999, Independencia, Santiago 8380456, Chile

Tel: +56-2-2978-8350, E-mail: anamariamadrid@gmail.com 


\section{Introduction}

Oddi sphincter's function is important in the regulation of postprandial flow of biliopancreatic secretion. The neurohumoral regulation of these small groups of smooth muscles is complex. Corresponding to this complexity, a considerable number of neurons was found in the sphincter region, almost comparable to the subserosal plexus of gallbladder. ${ }^{1}$ In addition, intrinsic innervation depends mainly on neuronal connections between the duodenal mucosa and the sphincter. ${ }^{2}$ The main extrinsic innervation is vagal. ${ }^{3}$ Acetylcholine stimulates the motor activity of the intact sphincter, ${ }^{4,5}$ the phasic contractions probably contribute in the injection of bile from the sphincter region to the duodenum ${ }^{6}$ and avoid the reflux of duodenal content to the bile duct. Buscapina (scopolamine butylbromide and hyoscine butylbromide), a nonselective muscarinic antagonist relaxes the sphincter, inhibits the duodenal motility and these effects permit its use as a spasmolytic, even in control of biliary pain. $^{7}$

Endoscopic sphincterotomy (EST) has become a treatment of choice in the extraction of bile duct stones. EST destroys the major part of the muscles of Oddi sphincter (OS), but this destruction is not always complete: variable degree of residual motor activity has been observed in patients after $\mathrm{EST}^{8-10}$ We have no data available about eventual changes of innervation of OS after EST.

In this paper we communicate a paradoxical stimulatory response to Buscapina observed in several patients after EST.

\section{Materials and Methods}

\section{Patients}

The study involved 14 patients (9 females and 5 males, mean age $50.4 \pm$ SEM 4.2 years, range $32-73$ years). All patients had a previous cholecystectomy.

\section{Motility Studies}

Endoscopic manometry of OS was performed after EST in order to control the residual motor activity of the OS. The patients were placed in the left lateral position, and they received $10 \mathrm{mg}$ diazepam intravenous (IV) injection as premedication. The motility of OS was studied by means of a 3-lumen perfused catheter (WilsonCook Medical Inc, Winston-Salem, NC, USA) which has 3 lateral orifices circumferentially orientated each $120^{\circ}$, with a distance of $2 \mathrm{~mm}$ between them. In addition, the catheter has 10 well visible marks with $2 \mathrm{~mm}$ distance between them, which permits evaluation of the profundity of the duct cannulation. The 3 lumens of the manometry catheter were perfused by sterile bidistilled water with a speed of $0.25 \mathrm{~mL} / \mathrm{minute} / \mathrm{lumen}$, by a pneumohydraulic capillary infusion system (Arndorfer Medical Specialty, Greendale, WI, USA). The intraluminal pressure was registered to external transducers (TP-400T) and connected to a polygraph (Nihon-Kohden Co, Tokyo, Japan). The diameter of sphincterotomy orifice was estimated comparing to the caliber of the manometry catheter: $5.5 \mathrm{~F}=$ $1.84 \mathrm{~mm}$ outer diameter. Pressure in the duodenal lumen was registered and considered as zero. Bile duct cannulation was confirmed by aspiration of yellow bile. Bile duct pressure was registered and the catheter was then slowly withdrawn into the sphincter region, where the residual motor activity was registered, as described previously. ${ }^{11}$ Independently of the basal manometry results, $20 \mathrm{mg}$ of Buscapina was injected IV and the sphincter pressure continuously registered at least for 5 additional minutes. Pancreatic duct was not cannulated and manometry of pancreatic sphincter segment was not performed in this group of patients. Duodenal peristalsis was estimated visually.

This work was approved by the Committee of Ethics for Clinical Research of Hospital Clínico Universidad de Chile (No. 24/20).

Table. Basic Demographic Characteristics of the Patients and the Estimated Size of Papillotomy Orifice

\begin{tabular}{cccc}
\hline Sex & Age $(\mathrm{yr})$ & $\begin{array}{c}\text { Time manometry- Orifice EST } \\
\text { EST (mo) }\end{array}$ & $(\mathrm{mm})$ \\
M & 38 & 9 & 9 \\
F & 65 & 1 & 12 \\
F & 53 & 56 & 5 \\
M & 48 & 40 & 8 \\
F & 68 & 36 & 15 \\
F & 65 & 12 & 15 \\
M & 47 & 15 & 10 \\
F & 59 & 6 & 10 \\
F & 40 & 13 & 8 \\
M & 32 & 5 & 10 \\
M & 64 & 12 & 8 \\
F & 56 & 12 & 10 \\
F & 34 & 12 & 5 \\
F & 57 & 7 & 8 \\
Mean \pm SEM & $50.4 \pm 4.2$ & $15.9 \pm 4.3$ & $10.4 \pm 1.3$
\end{tabular}

EST, endoscopic sphincterotomy; M, male; F, female. 


\section{Results}

The EST was performed with the aim to treat choledocholithiasis and the manometry was done 1 month to 56 months after the EST (mean \pm SEM: $15.9 \pm 4.3$ months). The papillotomy orifice was estimated between $5 \mathrm{~mm}$ to $15 \mathrm{~mm}$ (mean \pm SEM: $10.4 \pm$ 1.3), no significant stenosis was observed in this group of patients (Table).

Choledocho-duodenal pressure gradient was absent in all pa-

A

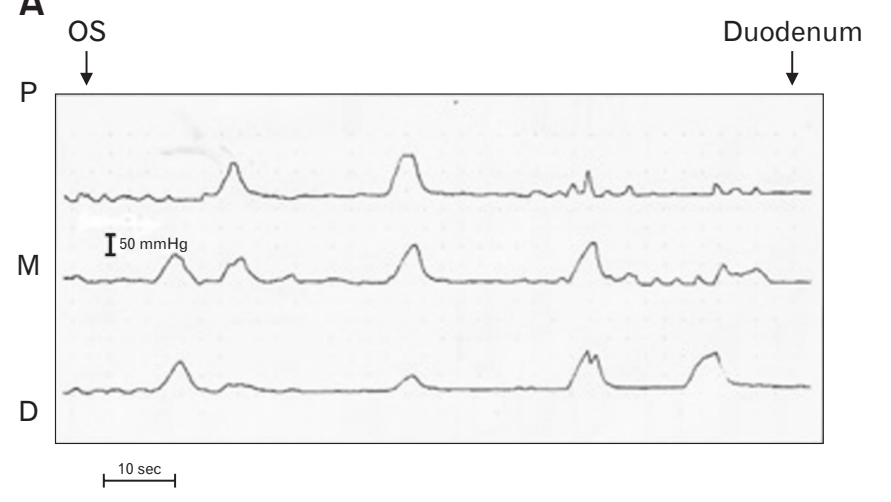

tients. The basal pressure of OS was zero in 7 patients and within the normal range, $7 \mathrm{mmHg}$ to $30 \mathrm{mmHg}$ in the other 7 . Residual motor activity was found in 11 of our 14 patients, detecting phasic contractions of $20 \mathrm{mmHg}$ to $130 \mathrm{mmHg}$ amplitude and 3/minute to $7 /$ minute frequency. Irregular contractions were observed in 2 cases.

We registered motor activity only with 2 of the 3 registry points in all but 2 of our patients after previous endoscopic papillotomy, as a signal of a short remnant sphincter segment. Buscapina IV injection inhibited the residual motor activity of sphincter in 3 patients, with a clear reduction of phasic contraction amplitude and

B

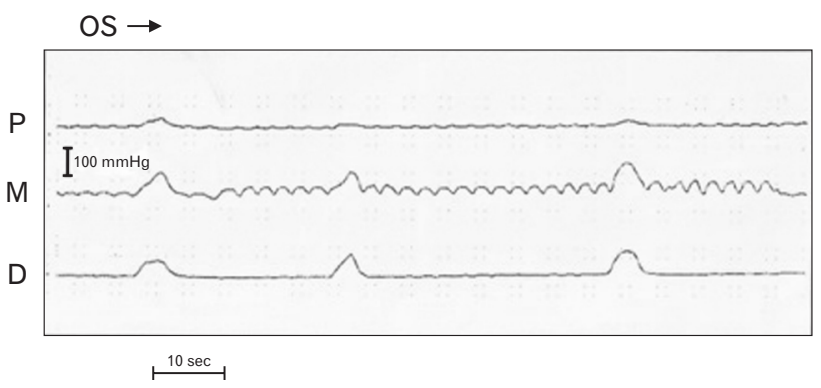

Figure 1. Inhibitory effect of Buscapina on phasic contractions. (A) Manometry after endoscopic sphincterotomy. Choledocho-duodenal gradient is zero, as well as basal sphincter pressure, but phasic contractions are present. Note different amplitudes in the 3 traces, which is the consequence of shorter functional sphincter segment and wider orifice. (B) Oddi sphincter (OS) activity after injection of Buscapina. A clearcut decrease in the amplitude of phasic contraction was observed, without significant difference in their frequency. Note the appearance of very quick small contractions resembling the form of saw teeth. $\mathrm{P}$, proximal point of register; $\mathrm{M}$, medium point of register; $\mathrm{D}$, distal point of register.
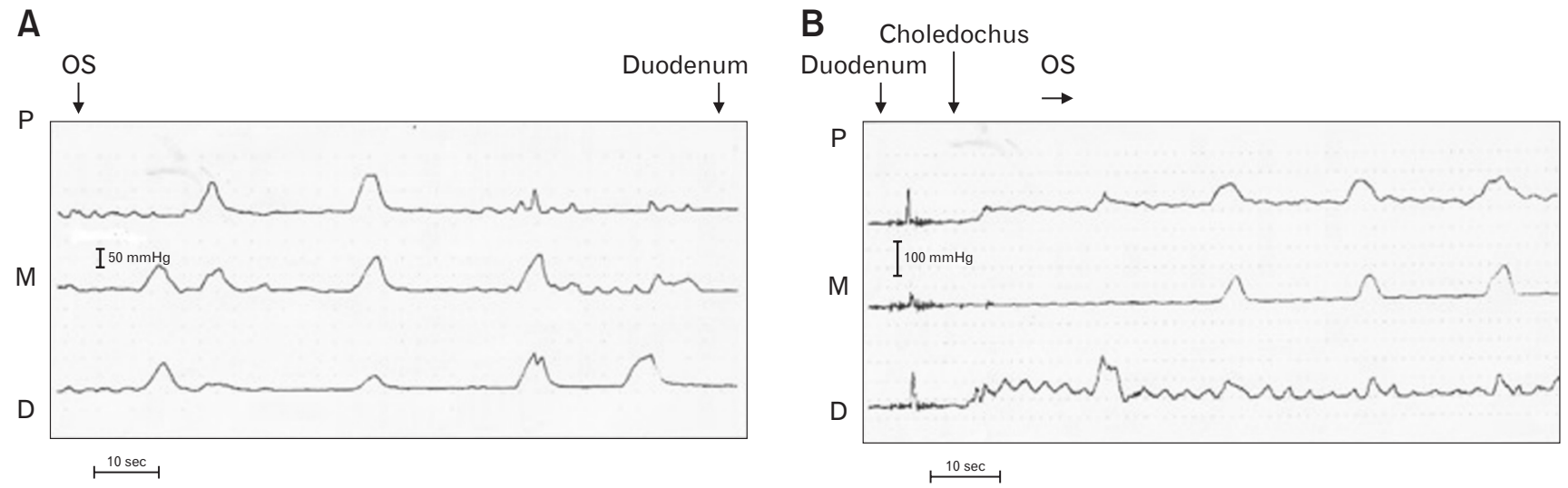

Figure 2. Buscapina stimulates the sphincter motor activity. (A) Representative manometry tracing after sphincterotomy, with a relatively wellpreserved sphincter function. Choledochus pressure: $0 \mathrm{mmHg}$ (not shown), basal sphincter pressure: $0 \mathrm{mmHg}$, Phasic contractions of $75 \mathrm{mmHg}$ amplitude and 3/minute frequency. (B) After Buscapina, the pressure in the choledochus continues to be zero, but sphincter basal pressure increases to about $20 \mathrm{mmHg}$ and again, an additional quick phasic contractile activity appears without evident changes in the previously registered contractions. Note the change in the sensitivity in the first segment of registry (see Fig. 2A). OS, Oddi sphincter; P, proximal point of register; M, medium point of register; $\mathrm{D}$, distal point of register. 
A

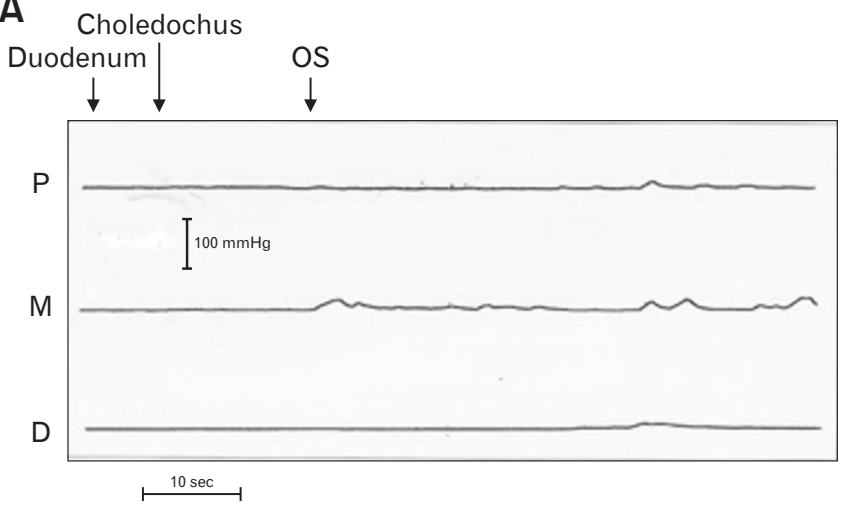

B

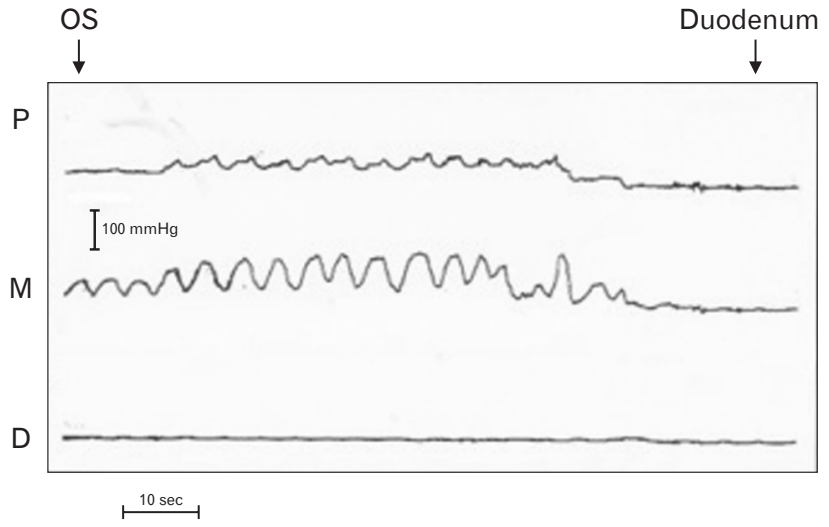

Figure 3. Marked motor activity after Buscapina. (A) A representative manometry registry in a patient after endoscopic sphincterotomy. The pressure in the main bile duct and the basal pressure of Oddi sphincter (OS) is $0 \mathrm{mmHg}$, some minimal residual irregular motor activity is detected. (B) Phasic contractions with a frequency of about 20 /minute and an amplitude of $60 \mathrm{mmHg}$ after the injection of Buscapina. In addition, a marked increase is registered in the basal sphincter pressure, to about $30 \mathrm{mmHg}$. P, proximal point of register; M, medium point of register; $\mathrm{D}$, distal point of register.
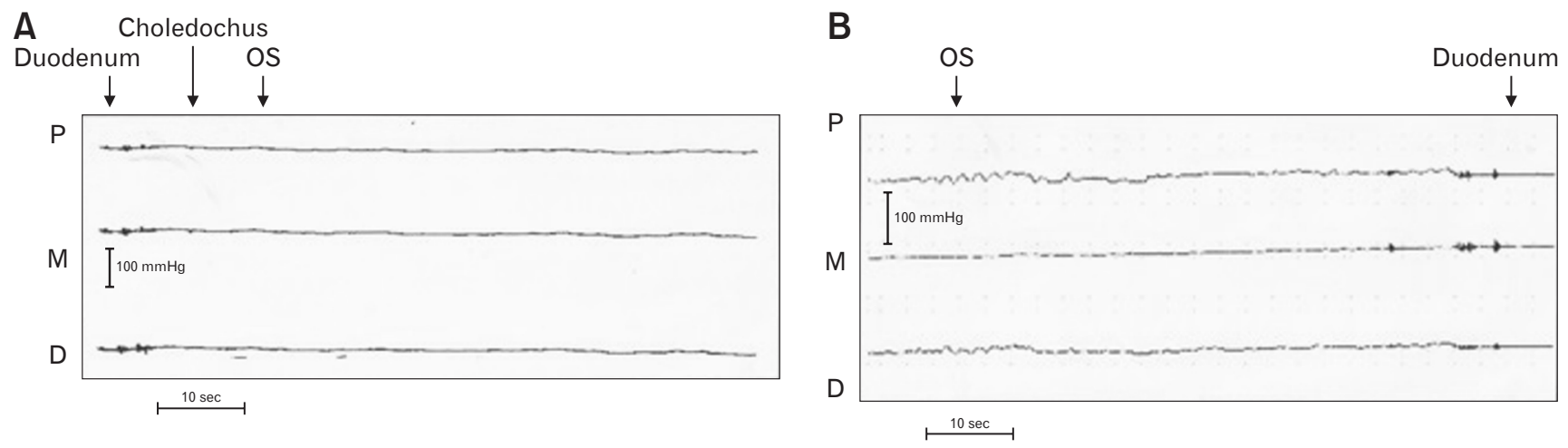

Figure 4. Increased basal Oddi sphincter (OS) pressure after Buscapina. (A) Absent sphincter function after endoscopic sphincterotomy. (B) Irregular quick phasic motor activity appears after Buscapina, with a detectable basal sphincter pressure about $5 \mathrm{mmHg}$. $\mathrm{P}$, proximal point of register; $\mathrm{M}$, medium point of register; $\mathrm{D}$, distal point of register.

frequency and minor variation of basal sphincter pressure (Fig. 1). These patients had a basal motor function of OS near to normal, with basal pressure of 7, 25, and $30 \mathrm{mmHg}$, respectively. In 2 patients with initial basal OS pressure of $0 \mathrm{mmHg}$ and $15 \mathrm{mmHg}$, Buscapina had no effect at all, the pressure values and contractions did not change after the injection. An unexpected stimulatory effect was observed in 9 patients, with initial basal OS pressure of 5, 10, and $25 \mathrm{mmHg}$ in 3 of them and $0 \mathrm{mmHg}$ in the remaining 6. An increase in basal OS pressure is seen in a patient with a relatively preserved sphincter activity (Fig. 2). Already in this case, very quick phasic contractions appeared in one of the traces. In other 2 patients with almost absent motor activity, a markedly increased basal OS pressure was detected with phasic contractions of high frequency and amplitude (Fig. 3). Minor similar changes were seen in another patient (Fig. 4). Similar phasic contractions of 20-40 $\mathrm{mmHg}$ but about 18-22/minute frequency appeared in 6 patients, in some of them also conserving the presence of phasic contractions observed before injecting Buscapina, with a slight increase in their frequency.

Evaluating together our 9 patients who presented a paradoxical stimulatory effect, a significant increase in basal sphincter pressure (Fig. 5A), in frequency (Fig. 5B) of phasic contractions was observed, with no significant changes in their amplitude (Fig. 5C). Duodenal peristalsis was invariably inhibited in all patients.

No relation was found between the response to Buscapina and the estimated size of papillotomy (Fig. 6A), neither the time elapsed since the endoscopic intervention (Fig. 6B). The size of papillotomy orifice did not vary depending on time (Fig. 6C). 
A

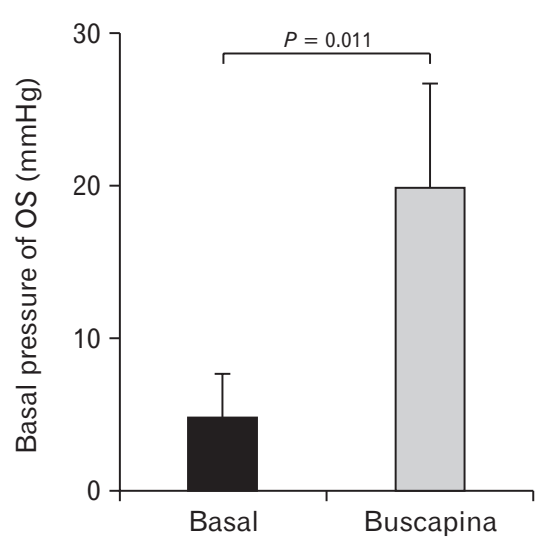

B

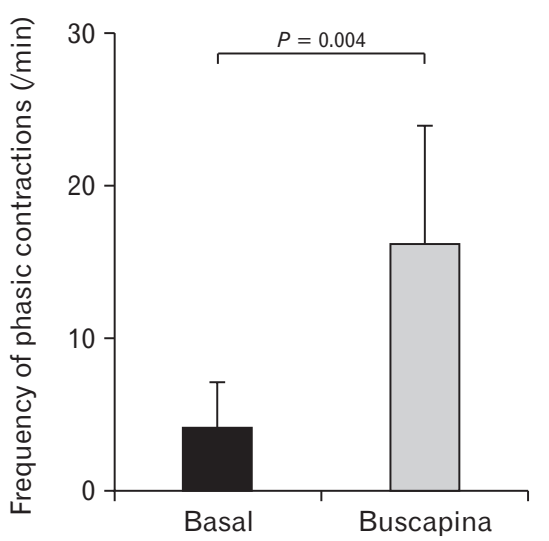

C

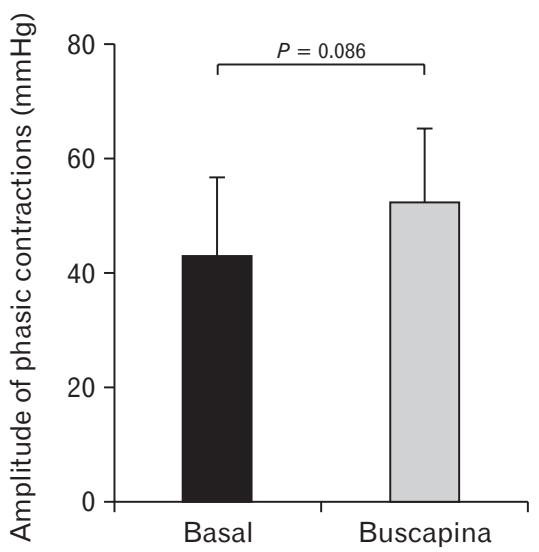

Figure 5. Manometry parameters in patients with paradoxical response to Buscapina. (A) Basal pressure of Oddi sphincter (OS) in the 9 patients with paradoxical response to Buscapina. (B) Frequency of phasic contractions in the 9 patients with paradoxical response to Buscapina. (C) Amplitude of phasic contractions in the 9 patients with paradoxical response to Buscapina. Values represent mean \pm SEM.

\section{Discussion}

EST is part of the endoscopic treatment of choledocholithiasis. It destroys variable fraction of the OS muscles and results in a loss of sphincter function in variable degrees. EST is considered as complete, if the pressure in the bile duct is equal to the duodenal pressure, and it means that the choledocho-duodenal gradient is zero. This criterion was accomplished in all our patients. The importance of preserved or lost OS function in the late outcome of these patients is not clear: Bergmann ${ }^{12}$ described a permanently lost sphincter function more than 10 years after EST, with basal sphincter pressure $0 \mathrm{mmHg}$. Others found preserved basal sphincter pressure, while with low normal values. ${ }^{9}$ Balloon dilation of the papilla instead of EST is supposed to preserve OS function, but no evident relation was demonstrated to the risk of stone recurrence or other late complications. ${ }^{8,10,13,14}$

These patients have a major probability to suffer abdominal cramps, biliary type pain, thus they receive frequently antispasmodic drugs, amongst them one of the most widely used is Buscapina. Being an anticholinergic agent, Buscapina inhibits the increased intestinal motility, cramps, and relaxes the normal OS.

The innervation of OS is complex. Stimulation of vagal fibers induces phasic contractions, on the contrary, Buscapina relaxes the normal sphincter. It has been routinely used in endoscopic retrograde cholangiopancreatography, in order to facilitate cannulation of the bile duct, inhibiting the duodenal motility and opening the OS. ${ }^{15,16}$ It is also frequently and safely administered in other routine endoscopic procedures. ${ }^{17}$ Paradoxical response of intact OS has been described to secretin in alcoholics ${ }^{18}$ and to cholecystokinin (CCK) in OS dyskinesia, ${ }^{19}$ but not to cholinergic agents or their antagonists. Our experiences represent the first observation and it was found only after EST and never with intact papilla. Even after EST, this effect is not the rule: 9 of 14 patients had this unexpected reaction, but we saw a habitual inhibitory effect in 3 and lack of change in 2 patients after Buscapina. No relation was found with the size of EST orifice, with the time elapsed between the EST and the manometry, nor with the age or eventual symptoms of the patient. It seems that the probability of paradoxical response increased as the functional destruction of the sphincter muscles was more important. The innervation of OS is complex and a closely connected duodeno-sphincteric circuit is described, which is mainly cholinergic in different species, ${ }^{1,20,21}$ but other neurotransmitters also participate in the regulation of motor function. It was demonstrated that neural transmission in this circuit was bidirectional. ${ }^{20}$ In the paper of Deng et al, ${ }^{22}$ the proximal duodenum close to the pylorus was transected and reanastomized. Followed this intervention, a slight decrease in basal OS pressure was observed and CCKoctapeptide injection produced a paradoxical stimulatory response, high amplitude phasic contractions instead of sphincter relaxation observed before the transection. Dong et $\mathrm{al}^{23}$ performed duodenectomy and gastro-jejunostomy in dogs and inserted the intact papilla in the "neoduodenum" formed by the jejunum. In these dogs, no inhibitory effect was observed after CCK injection. In any of these experimental settings, once the duodenal continuity was interrupted, CCK did not produce more OS relaxation. 

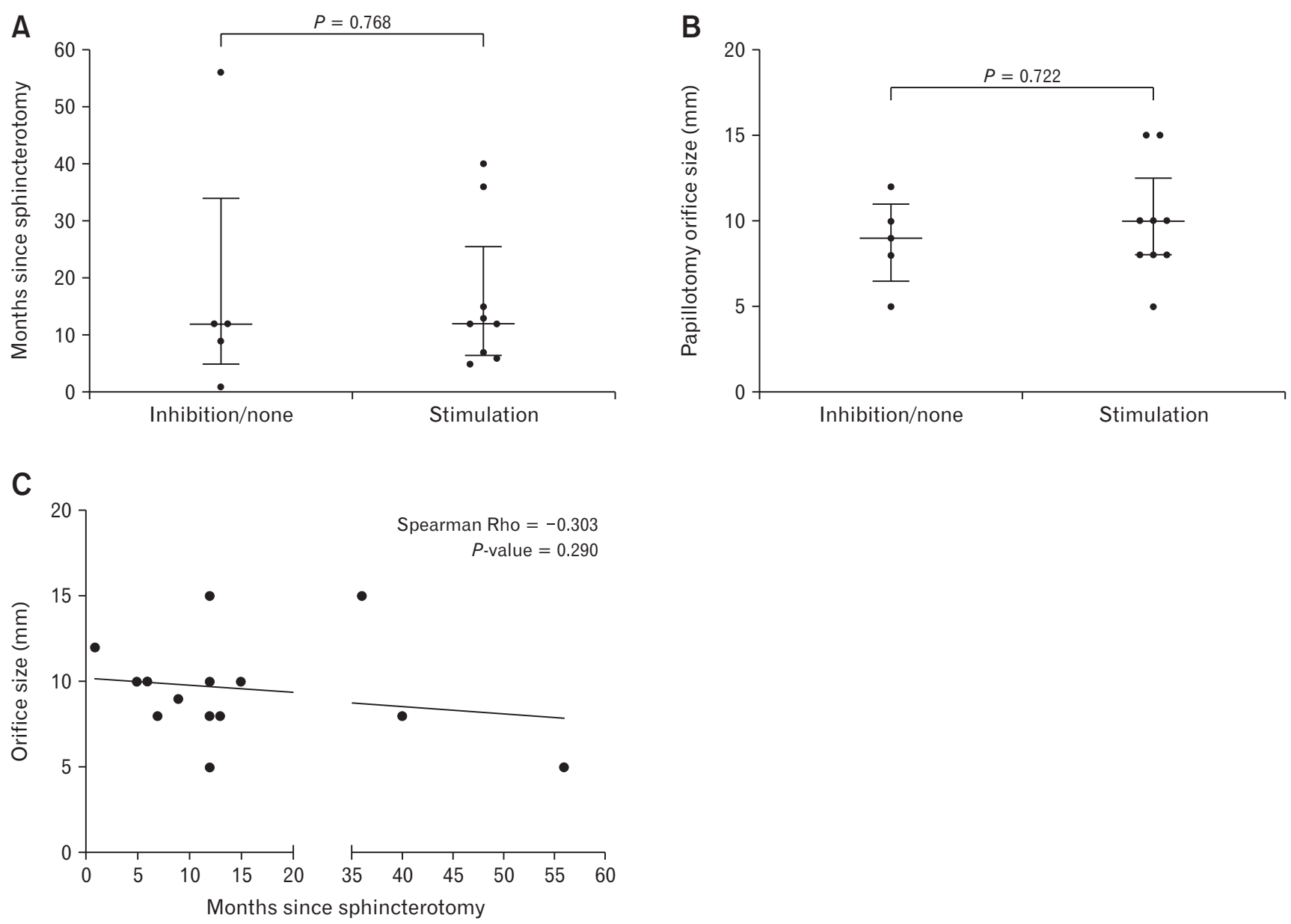

Figure 6. Size of papillotomy orifice, response to Buscapina and the time after endoscopic sphincterotomy (EST). (A) Time elapsed between the EST and the manometry. Mean \pm SD and the dispersion of values in the group of patients with normal inhibitory or no response to Buscapina and in the group of patients presenting stimulatory effect. No significant difference was found. (B) Estimated papillotomy orifice size in the 2 groups of patients, with normal or absent vs paradoxical stimulatory response to Buscapina. Mean \pm SD and the dispersion of values is depicted. No significant difference was found. (C) Estimated size of papillotomy orifice in relation to the time elapsed since the endoscopic sphincterotomy. No significant relation was found.

EST destroys not only muscular elements of the OS, but probably interrupts the integrity of duodeno-sphincteric circuit and changes the proportion of stimulatory and inhibitory fibers. One can speculate that Buscapina in these cases blocks the inhibitory vagal fibers, which permits a consecutive dominance of stimulatory, probably non-cholinergic fibers. Endoscopic manometry is an invasive method with risk of complications, for this reason we did not try to search for the antagonist of this stimulatory effect. It is worthwhile to remark, that the paradoxical effect of Buscapina was only observed in the motor function of OS, the powerful inhibition of duodenal peristalsis was unaltered. Thus, the EST interferes exclusively with the innervation of OS but not with that of the duodenum.
In conclusion, we report a paradoxical stimulatory effect of an anticholinergic agent, Buscapina observed in 9 patients treated previously by EST. Apart from destruction of variable fractions of OS muscle, this endoscopic intervention probably interrupts the duodeno-sphincteric circuit of nerve fibers, and alters the proportion of stimulatory and inhibitory components. The partially preserved OS muscles respond with paradoxical contractions in several patients. This effect seems to be related rather with the individual variations of length of OS and its nerve fibers and ganglia than the technical aspects of EST. The clinical importance of this phenomenon is not clear but it seems reasonable to avoid the use of Buscapina in patients after EST for the treatment of abdominal cramps, eventually of biliary origin. 
Acknowledgements: The authors acknowledge the skilled technical assistance of Silvana Riquelme and José Matus (deceased); and Abraham Gajardo Cortez's assistance in statistical analysis.

Financial support: This work forms part of project (No. 1950290 FONDECYT).

\section{Conflicts of interest: None.}

Author contributions: Zoltán Berger and Ana María Madrid $\mathrm{S}$ participated equally in the design and execution of the work, as well as in the recollection and interpretation of data, and redaction and critical revision of manuscript.

\section{References}

1. Balemba OB, Salter MJ, Mawe GM. Innervation of the extrahepatic biliary tract. Anat Rec A Discov Mol Cell Evol Biol 2004;280:836847.

2. Bosch A, Peña LR. The sphincter of Oddi. Dig Dis Sci 2007;52:12111218.

3. Toouli J. Sphincter of Oddi: function, dysfunction, and its management. J Gastroenterol Hepatol 2009;24(suppl 3):S57-S62.

4. Woods CM, Saccone GT. Neurohormonal regulation of the sphincter of Oddi. Curr Gastroenterol Rep 2007;9:165-170.

5. Toouli J, Baker RA. Innervation of the sphincter of Oddi: physiology and considerations of pharmacological intervention in biliary dyskinesia. Pharmacol Ther 1991;49:269-281.

6. Afghani E, Lo SK, Covington PS, Cash BD, Pandol SJ. Sphincter of Oddi function and risk factors for dysfunction. Front Nutr 2017;4:1-9.

7. Tytgat GN. Hyoscine butylbromide: a review of its use in the treatment of abdominal cramping and pain. Drugs 2007;67:1343-1357.

8. Li T, Wen J, Bie L, Gong B. Comparison of the long-term outcomes of endoscopic papillary large balloon dilation alone versus endoscopic sphincterotomy for removal of bile duct stones. Gastroenterol Res Pract 2018;2018:6430701.

9. Suarez AL, Pauls Q, Durkalski-Mauldin V, Cotton PB. Sphincter of Oddi manometry: reproducibility of measurements and effect of sphincterotomy in the EPISOD study. J Neurogastroenterol Motil 2016;22:477-482.

10. Cheon YK, Lee TY, Kim SN, Shim CS. Impact of endoscopic papillary large-balloon dilation on sphincter of Oddi function: a prospective randomized study. Gastrointest Endosc 2017;85:782-790, e1.
11. Berger Z, Pimentel C, Madríd AM, Defilippi C. [Endosopic manometry oh Oddi's sphincter.] Rev Med Chil 1997;125:1343-1350. [Spanish]

12. Bergman JJ, van Berkel AM, Groen AK, Schoeman MN, Offerhaus J, Tytgat GN, Huibregtse K. Biliary manometry, bacterial characteristics, bile composition, and histologic changes fifteen to seventeen years after endoscopic sphincterotomy. Gastrointest Endosc 1997;45:400-405.

13. Yasuda I, Tomita E, Enya M, Kato T, Moriwaki H. Can endoscopic papillary balloon dilation really preserve sphincter of Oddi function? Gut 2001;49:686-691.

14. Suarez AL, Coté GA. Can we preserve sphincter of Oddi function by avoiding sphincterotomy? Do we want to? Gastrointest Endosc 2017;85:791-793.

15. Hannigan BF, Axon AT, Avery AT, Thomspon RP. Buscopan or glucagon for endoscopic cannulation of ampulla of Vater? J R Soc Med 1982;75:21-26.

16. Garrigues V, Ponce J, Pertejo V, Sala T, Berenguer J. Effects of atropine and pirenzepine on sphincter of Oddi motility. A manometric study. J Hepatol 1986;3:247-250.

17. Lee T, Anderson J, Thomas-Gibson S, Rees C. Use of intravenous hyoscine butylbromide (buscopan) during gastrointestinal endoscopy. Frontline Gastroenterol 2018;9:183-184.

18. Laugier R, Gerolami R, Renou C. Sphincter of Oddi manometry: paradoxical response to secretin but not to $\mathrm{CCK}$ in alcoholic patients with no pancreatic disease. Int J Pancreatol 1998;23:107-114.

19. Rolny P. Arlebäck A, Funch-Jensen P, Kruse A, Ravnsbaeck J, Järnerot G. Paradoxical response of sphincter of Oddi to intravenous injection of cholecystokinin or ceruletide. Manometric findings and results of treatment in biliary dyskinesia. Gut 1986;27:1507-1511.

20. Kennedy AL, Saccone GT, Mawe GM. Direct neuronal interactions between the duodenum and the sphincter of Oddi. Curr Gastroenterol Rep 2000;2:104-111.

21. Simula ME, Harvey JR, Costi D, Baker RA, Toouli J, Saccone GT. In vitro characterization of intramural neural pathways between the duodenum and the sphincter of Oddi of the brush-tailed possum. J Auton Nerv Syst 1997;63:77-84.

22. Deng ZL, Nabae T, Konomi H, et al. Effects of proximal duodenal transection and anastomosis on interdigestive sphincter of Oddi cyclic motility in conscious dogs. World J Surg 2000;24:863-869.

23. Dong M, Sonoda Y, Kawamoto M, et al. Duodenum is important for the sphincter of Oddi motor response to cholecystokinin octapeptide in conscious dogs. J Gastroenterol 2005;40:389-395. 